\title{
'Embodying’ Dirty Work: A Review of the Literature
}

\author{
Ruth Simpson
}

Brunel University

\section{Alexander Simpson}

University of Brighton

\begin{abstract}
This article reviews the growing literature on dirty work i.e. work that is seen as disgusting or degrading and argues for a more 'embodied' understanding of such work. It points to a tendency in the literature to focus on the nature of the task or role and on social and moral dimensions of the work at the expense of its material and embodied aspects. The latter are discussed through three, interrelated themes: ‘embodied suitability’ whereby forms of dirty work are seen as suitable for some 'working bodies' and not for others; 'staining' which is presented as both a material and a symbolic process; and the role of work practices in both supporting and undermining ideological constructions around the work. The article concludes by arguing for a more comprehensive approach which includes both the material and the symbolic into accounts of such work.
\end{abstract}

Key words: dirty work, embodiment, staining, practice 


\section{Introduction}

This article reviews some of the key literature on dirty work and argues for a more 'embodied' understanding of how such work is defined and experienced. Dirty work is generally defined as tasks, occupations and/or roles that are likely to be perceived as disgusting or degrading (Ashforth and Kreiner, 1999) i.e. which are seen as physically, socially and/or morally tainted. Dirty work has, until recently, been largely neglected within the fields of Organization Studies and the Sociology of Work (Ashforth and Kreiner, 1999; Dick, 2005) - an oversight that Bolton (2007) has associated with a ‘narrow vision’ among policy makers that has promoted and prioritised 'clean', high skilled and 'better' work, despite the fact that such work has not always been widely available (Simpson et al, 2012; Atkinson et al, 2012). However, drawing on the early work of Everett Hughes (1962) in his text Good People and Dirty Work, a growing interest has been shown in recent years in forms of work that might come under this broad category.

As we argue in this article, while this interest is a welcome one in putting an often invisible form of work 'on the map', the main focus within the literature has been on occupational features (e.g. the nature of the work and the tasks involved) and on ideological strategies to manage taint, discussed further below. This, however, neglects some of the work’s ‘embodied aspects'. This may include the influence of the meanings ascribed to the bodies of those undertaking the work (based on gender, class, age, race), the physical and symbolic dynamics involved in 'staining'where dirty work can, in different ways, mark both the body and the sense of self - and the implications of 'embodied practices' (effort, skill) for how the work is encountered. Promoting 
an 'embodied' account of such work is therefore to recognise how social attributes mapped onto (gendered, raced, classed) bodies construct hierarchical divisions of labour and evaluations of worth (McDowell, 2009); how the material (e.g. in the form of physical staining) impacts on the meanings created around the work (Vachhani, 2012); as well as of how embodied, material practices are implicated in the production of a work-based identity (Pullen and Simpson, 2009). In reviewing the literature, the article highlights a need to incorporate both the symbolic and the embodied/material dimensions of dirty work and shows how these two dimensions are inextricably intertwined. This extends our understanding of dirty work by including the fundamental significance of the identity categories attached to the bodies performing the work as well as some of the physical aspects involved in the work's practice and performance.

\section{Symbolic Dimensions of Dirt and Dirty Work}

Influenced by Mary Douglas’s (1966) seminal work on the symbolic dimensions of dirt - seen as 'disorder' and as 'matter out of place' - much of the literature on dirty work has adopted a socially constructionist perspective where dirt is seen as 'in the eyes of the beholder', subject to particular perceptions and contingencies. This focuses on the meanings afforded to dirt based on different perceptions of how it has, in Douglas's terms, 'violated' a cultural order, rather than on the possession of any essential attribute (Hughes et al, 2016). Cleanliness and dirt therefore are seen as having a social and moral, rather than material, significance. Thus, as referred to above, avoidance rules often mean that occupations which deal with polluting, physical dirt are carried out by those who are separated spatially and socially from other groups (Dick, 2005). Within the hospital setting, for example, much of the work of bodily, intimate care is carried out by general nursing staff or by hospital orderlies with doctors avoiding these (more messy) day to day 
routines. Dirt and dirty work are therefore tied up with a moral and social order with implications for prestige, work hierarchies and social positioning.

Following the above, as Dant and Bowles (2003) argue, while there are social and moral elements involved in dirty work, there is also a materiality (based for example on bodily sensations of smell, touch, stickiness and slime) that is largely overlooked in the literature. This material element was acknowledged in part by Everett Hughes (Hughes, 1962) who identified dirty work as physically disgusting, as counter to moral conceptions and/or as symbolic of social degradation, thereby giving recognition to the work's physical dimensions as well as to its social and moral basis. These dimensions were developed by Ashforth and Kreiner (1999) in an article published in the Academy of Management Review which presented a typology of dirty work that has become foundational for much of the work in the field. Here, they delineated three forms of taint based on different occupations or roles: physical taint covers work that is associated with dirt or danger such as refuse collectors or miners; social taint relates to work that involves regular contact with people from stigmatised groups and/or which is seen as servile to others such as prison officers or domestic cleaners; and moral taint which refers to work that is regarded as sinful or of dubious virtue such as debt collectors or sex workers. However, while the concept of physical taint has potential to incorporate some of the embodied, physical dimensions of dirty work, the focus is still on this form of work's socially constructed nature through an emphasis on meanings and perceptions, from the perspective of 'the beholder', rather than on any intrinsic, physical dirtiness of the job.

This focus on perceptions and meanings is evident in more recent accounts (Kreiner et al., 2006) that have developed notions of the 'breadth' and 'depth' of perceived dirtiness. Breadth refers to 
the proportion of the work that is perceived to be dirty or the centrality of dirt to the occupational identity (a physician may occasionally deal with dead bodies, but a mortician always does so). Depth captures the intensity of dirtiness and the extent to which a worker is seen to be directly involved. For example, drawing on examples from Kreiner et al (2006), police officers may routinely deal with criminals (high intensity), while security guards mostly deal with the public (low intensity). Some occupations may have high breadth and depth because of a single dimension (e.g. the moral taint of prostitutes, the physical taint of sewage workers). By contrast, other occupations may be low on both dimensions. This classification therefore captures a wider group of occupations or roles beyond the 'extreme’ cases identified by Ashforth and Kreiner above. However, while some significance is attached to practices, it is still oriented towards perceptions of dirtiness over any intrinsic elements. Taken together, as Hughes et al (2016) point out, the literature has developed around an orientation to dirty work based on a classification of task or role, and has preferred an understanding of dirt as a social rather than a material entity, foregrounding the significance of perceptions of and meanings constructed around the work.

\section{Ideological Strategies to Manage Taint}

This emphasis on the symbolic can also be seen in work that has focussed on how taint is managed. The idea of dirt as a contravention of social order that transgresses particular boundaries means that those involved in dirty work can be stigmatised, morally and socially, through association. As Goffman (1963) has argued, dirt has potential to produce stigmatising conditions so that individuals are 'tainted' and disqualified from full social acceptance, making identity management problematic (Bolton, 2005; Dick, 2005; Newman, 1999). 
Ashforth and Kreiner (1999) identify various ‘normalisation’ strategies that involve processes of meaning making and 'perceptual reordering' in order to render the work acceptable and ordinary (see also Ashforth et al., 2007). Drawing on social identity theory, which foregrounds the significance of group membership and the desire for a positive identity in the 'eyes of others', they identify various ideological strategies that serve to counter the tainted associations with the work and to enhance how it is perceived. Some research, for example, has highlighted how demonstrating mastery of the dirtiest aspects of the job can be a source of value. Thus, care workers can find a sense of distinctiveness, pride and moral authority in the ability to undertake work that others would be too ‘squeamish’ to perform (Stacey, 2005; 2011). Hughes et al (2016) refer to how refuse collectors gain satisfaction from doing an essential service under difficult conditions and how this engenders a strong occupational and workgroup culture. As Ashforth and Kreiner (1999) argue, individuals often recast their dirty work in affirmative terms through work group cultures and occupational ideologies (e.g. around fortitude and toughness) that highlight group cohesion, articulating occupational identity in terms of 'us and them' and focussing on the specific demands of the job. This can be done by 'reframing' the meaning of dirty work by infusing it with positive value (e.g. seeing such work as a badge of honour or a mission); 'recalibrating', that is adjusting the perceptual and evaluative standards used to assess the work and thereby minimising the 'dirty work' component (e.g. hospital cleaners may introduce notions of patient care as integral to the work); and 'refocusing' through the shifting of attention away from the stigmatised to the non-stigmatised features of the job (e.g. refuse collectors may focus on the benefits of social solidarity and of working outside). Overall, as Kreiner et al. (2006) argue, individuals engage in a diverse set of coping strategies grounded in 
group membership and the need to shape a positive identity in order to deal with stigma at work. However, as Dick (2005) points out, this social-identity approach tends to privilege cognitive aspects of identification based on individuals' knowledge of group membership to the detriment of an appreciation of broader social processes and contextual factors. In this respect, occupational and social positioning, organizational structures and 'extraorganizational discourses' (Tracy and Scott, 2006) might actively impinge upon the meanings ascribed to work tasks and upon how work-based identities are constructed, negotiated and maintained.

In response, other research has adopted a more post-structuralist perspective that foregrounds the relation of the individual to broader social and institutional orders and where 'meaning making', rather than seen as a largely cognitive process based on knowledge of group membership, is located within the wider political and social context. The emphasis therefore is on the contextually contingent ability of individuals to mobilize discursive resources to manage tainted work (e.g. Dick, 2005; Tracy and Scott, 2006; Toyoki and Brown, 2014) where identity is less tied to group membership but seen as fragile and emergent, produced through interaction and discourse. The strategies outlined above (reframing, recalibration, refocusing) will therefore be the result of 'discursive struggles' based on an individual's ability to mobilise social and cultural resources to support (or resist) a particular sense of self. Thus, from Dick’s (2005) study, police officers were able to reconstruct occupational identity by bringing meanings of coercive authority into line with dominant ideals of a liberal democratic society and so were able to absolve themselves of personal responsibility for the 'moral taint' of the use of force. Simpson et al (2012) found that male nurses drew on traditional gender hierarchies to mobilise hegemonic discourses of masculinity, presenting themselves as able to deal with difficult patients and 
thereby overcoming damaging associations with femininity and with the practices of bodily care. Therefore, while social identity theory and the post-structuralist approach share an emphasis on the meanings constructed around the work as well as an orientation towards dirt as socially constructed in nature, the latter highlights how these meanings are situated within specific social and ideological contexts and are open, as Dick (2005) contends, to contestation and dispute. In other words, from this perspective, larger discourses, structures and contexts are seen to both enable and constrain identity production at work (Tracy and Scott, 2006).

\section{Gender, class and race and 'embodied suitability'}

The literature reviewed so far has tended to equate dirty work with particular occupations or roles (based on physical, social and moral taint) and to place emphasis on the meanings and ideologies constructed around such work - either with reference to group membership and the need to manufacture a positive identity or in relation to discursive strategies that help to manage taint. However, with some notable exceptions (e.g. Bolton, 2007; Tracy and Scott, 2006) much of this literature tends to overlook how perceptions and experiences of dirty work and the ways in which taint is managed are likely to be strongly affected by identity characteristics of workers based, for example, on gender, race, nationality and class. In this respect, the notion of 'embodied suitability' (Simpson et al, 2012) captures the idea that some forms of work are seen as appropriate for some groups and not for others. As McDowell contends, looking at gender and interactive service work, 'embodied characteristics' based on skin colour, weight or height, accent and stance produce a 'finely graded set of evaluations that position workers as more or less suitable to perform different types of work' (McDowell, 2009: 14). 
In support of this idea of 'suitability', many of the dirty work occupations or roles undertaken are drawn on traditionally gendered lines. Socially tainted work based, for example, on service and care have strong associations with the characteristics (e.g. of deference, sensitivity, nurturance) that society normally attaches to women, while forms of work involving physical taint (e.g. heavy manual labour, work involving risk or danger) are traditionally the domain of men. Research in these areas has accordingly explored the experiences of women as care workers or domestic helps (e.g. Anderson, 2000) and as sex workers (e.g. Mavin and Grandy, 2012) while other scholarship has considered the physical taint of male mechanics (Dant and Bowles, 2003), male slaughtermen and butchers (Ackroyd and Crowdy, 1990; Simpson et al, 2014). Class, race and migrancy are further categories of difference that potentially influence how the work is experienced and perceived. Physically tainted work (e.g. street cleaning, refuse collection, construction) is often - though not exclusively - undertaken by those who occupy a 'working class' social positioning (Simpson et al., 2014; Hughes et al., 2016; Thiel, 2007). In the context of domestic service and pointing to the disproportionately high employment of racial-ethnic women, Duffy (2007) has pointed to the gender and race typing of such work, with black and migrant women employed in private, domestic work while migrant men are often found within institutional cleaning, where, as Anderson (2000) argues, they are effectively 'de-gendered' by race and citizenship. There is thus an 'overlap’ between forms of low status dirty work and categories of socio-economic and/or demographic status. Here, Ashforth and Kreiner (2014: 430) refer to a 'recursive loop’ whereby 'questionable essentialist stereotypes' take on a normative slant and where low-prestige dirty work is devolved to marginalised demographic categories, reinforcing the relationship between the two. 
These categories of difference, as Tracy and Scott (2006) have pointed out, while crucially important in terms of understanding the experiences and perceptions of the work, are often peripheral to the analysis and are implicit rather than explicit in many accounts. So while, with a focus on gender, issues of masculinity and femininity are present in some of the dirty work literature as above, such work often neglects the ways in which gender may be fundamental, as an analytical point of departure, in accounting for how such work is constituted and how taint is navigated. In other words, explicit recognition needs to be given to how bodies are inscribed with gendered, raced and classed occupational discourses and meanings and how some skills and attributes may be devalued - and seen as 'tainted' - depending on who practices and embodies them.

Thus, Lee-Treweek (2012) notes, in one of the few studies to give such recognition, how migrancy is strongly implicated in how dirty work is experienced in a context where migrants routinely undertake 'unwanted' labour. While such work is routinely rejected by indigenous workers due to poor conditions and pay, migrants are nevertheless often subject to 'moral taint' based on perceptions that they are 'stealing' jobs. Simpson et al (2012) similarly show how the intimate and messy bodily care work of nursing is difficult to combine with ideas of (white, heterosexual) masculinity and how men are often 'fast-tracked' into cleaner i.e. more technical roles. Here, 'caring' work is often afforded greater value when undertaken by men (seen as a 'special contribution') while for women, caring is devalued as a 'natural' part of femininity. Meanings related to (white, heterosexual) men’s bodies (rationality, detachment, cleanliness) are 
accordingly seen as incongruent with the 'dirtier' demands of nursing care (Evans, 2002), suggesting how some bodies (female, black, migrant, gay) are seen as suitable for some forms dirty work and how these bodies can be seen to carry dirt's stigma.

Cleanliness and dirt are accordingly inscribed onto particular bodies, affording them different levels of value with implications for how the work is perceived. Perhaps as a result, some members of occupations have fewer 'status shields' than others: female correction officers are subject to more harassment from inmates than men and female cabin crew are subject to greater service demands from passengers whilst enduring more 'belittling comments' than male crew (Britton, 1997; Simpson, 2009). This suggests that forms of dirty work may appear be 'suitable' for some groups rather than others and that experiences of dirty work and perceptions of taint may well depend on these demographic and 'bodily' dimensions.

\section{Symbolic and Material Staining}

As Grandy et al (2014) note, stains and staining are inevitably implicated in how dirty work may be understood. Here, as noted above, symbolic staining can emerge from dirty work involving moral taint and/or social taint that 'rubs onto' (Bergman and Chalkley, 2007) those performing it, 'staining' character and the sense of self. Drawing on a well-established orientation to dirt as moral transgression and 'disorder' (Douglas, 1966), and as much of the literature on ideological strategies to manage taint referred to above suggests, those involved in dirty work can become stigmatized, in a symbolic sense, as a result. Sex workers for example attract disapproval based on a moral order around the gendered 'whore stigma' (Grandy and Mavin, 2012). In the context 
of social taint, Newman (1999) looking at the fast food industry found attitudes of disrespect from customers towards 'front-line’ workers to be a routine part of day-to-day experience.

Dirt however is not just a symbolic or cultural entity but has a physical and visible presence, materialized in, as example, sliminess and/or stickiness that can adhere to and stain clothing and the skin. Physically tainted work may involve contact with defiled matter (bodily fluids, grime, waste) that is rendered offensive in bodily terms through smell and touch. Blood and offal can become lodged under the fingernails of butchers arousing disgust on the part of family members (Simpson et al, 2014) while refuse collectors must shower to remove the smells accumulated through repeated contact with waste during the course of the day (Hughes et al, 2017).

As Vachhani (2012) notes, stains associated with filth, grime or muck can pose a threat and trouble a moral order, indicating that physical stains have both a symbolic and a material presence. Capturing the interconnectedness between the symbolic and the material, she shows how physical staining can find expression and meaning in a variety of ways. Wolkowitz (2007), for example, draws attention to the class and gender implications of work with physical dirt where dirt has historically been associated with the working class woman's body, allowing white middle class women to develop an image of 'disembodied purity' and to be seen as 'stain free'. However, Vachhani contends that stains in the form of bodily fluids and other visceral matter may not always be seen as compromising or as a source of vulnerability, but can be reconfigured as productive. Ackroyd and Crowdy's (1990) study of slaughtermen showed how men preserved stains from blood and gore on their clothing as a source of masculine pride and Jervis's (2001) 
study of incontinence care found that some workers confronted and even welcomed stains (e.g. by not wearing gloves) to give them a sense of moral authority based on their capacity to 'stomach' the dirtiness of the job.

This suggests an interplay between the material and the symbolic in terms of how staining is encountered and managed and a 'productivity' in the marking that partly operates through the body. As Vacchani notes, bodily stains associated with proximity to visceral forms of matter such as bodily fluids, muck or grime, 'take shape' in specific contexts of social differentiation and power, associated for example with different levels of vulnerability and capacities to reconfigure stains in a positive way. As Tracy and Scott (2006) illustrate, drawing further on Ackroyd and Crowdy’s (1999) study above, slaughtermen were able to draw on traditional masculinity as a key discursive resource to present stains as a source of pride, thereby differentiating themselves in affirmative terms from women. However, as they note (and Jervis’s study is a potential exception here), there is less evidence to support the view that domestic or care workers wear the dirt associated with their jobs (dust, scum, vomit, excrement) as a badge of honour; instead they seek to remove it. The lower status of the work in this context and associations with a devalued feminine mean there are fewer resources open to create positive value. Therefore, rather than relying on the symbolic for an understanding of the effects of stains and of staining, often seen as a potential source of social stigma or shame, this suggests the necessity of incorporating the complexities involved in how the material interacts with the symbolic. An understanding of dirty work therefore needs to recognize the ways in which 
physical stains are ‘framed’ within particular sets of social relations and how, differentially, they are given meaning - with implications for how such markings are negotiated and managed.

\section{Material Conditions and Practices}

The above suggests a need to fully incorporate the materiality or physical manifestation of dirt in understandings of how dirty work is encountered and experienced. As we suggest in this section, this also involves acknowledgment of the significance of material practice such as those involved in dirt's handling or removal. Here, practice can be seen as a 'routinized' nexus of 'doings' in which ‘bodies are moved, objects are handled, subjects are treated’ (Hardy and Thomas, 2014). As we have seen, while physical taint has potential to incorporate the materiality of dirt, the literature has preferred, in large, to focus on ideological constructions whereby dirt and dirty work are seen to shift in form according to cultural constructions and perceptions, so that even the nature of physical taint lies 'in the eye of the beholder' (Ashforth and Kreiner, 1999). There are, however, some exceptions to this tendency. Thus, a genre of research has explored the 'intimate messy contact’ involved in different forms of 'body work’ (Wolkowitz, 2002) including a range of studies focusing on the significance of the dirt, cleanliness and continence in bodily care (e.g. Anderson, 2000; Twigg, 2004; Jervis, 2001). However, as Hughes et al (2016) suggest, the above work notwithstanding, the literature has tended to mature around an understanding of dirty work as culturally and socially prescribed, with responses to dirt construed as primarily ideological in form.

Highlighting the significance of the material in dirty work, Hughes et al demonstrate through their study of street cleaners and refuse collectors how ideological strategies to manage taint as 
outlined by Ashforth and Kreiner (1999) above (e.g. reframing, refocusing) are underpinned by and inseparable from material conditions and practices. Thus, satisfaction gained from doing an essential service, moral value drawn from restoring cleanliness and/or pride in withstanding the rigors of the work are underpinned by and dependent upon work practices based on hard, physical labour, bodily effort and the physical activities around dirt's removal. In a process of 'reframing', moral value was emphasized through participants' ability to create order out of the disorder of dirt. As they show, proximity to dirt could be partially redeemed, and moral value restored, through bodily effort and participation in the practices and routines of restoring cleanliness, allowing participants to create meanings around the work's usefulness and importance.

In an earlier study (Simpson et al, 2014), they similarly demonstrate how butchers draw pride from their ability to withstand the cold from working in refrigerated conditions as well as from the practice of skills in 'cutting down' a carcass and from physical dexterity (speed, precision) in working with knives. While this is generally not given explicit recognition in the dirty work literature, positive reframing can accordingly be underpinned and supported by material conditions and material practices based on, for example, hard work, effort, fortitude and the deployment of skills.

By the same token, however, as Hughes et al (2016) point out, material conditions can undermine positive constructions around the work. Thus, bodily fatigue from physical effort and from a long working day and/or feelings of disgust based on the need to handle some forms of matter (excrement, rotting food) can interfere with ideological constructions around, as example, 
camaraderie, pride in a job well done or the pleasures of working outside. As they point out, bodily exhaustion (monotony, tiredness and physical strain) and the enduring repulsion felt towards some forms of waste can 'destabilize' and 'disrupt' attempts positively to reframe the work’s significance. Thus, a pleasant banter between members of the refuse collection team often died down towards the end of the day as the onset of fatigue as well as the pressure to complete the work before the end of the shift interfered with a valued camaraderie. Moreover, as they highlighted, face to face encounters with members of the public based on attitudes of disrespect could comprise a devaluation that is not just symbolic but has an embodied and material dimension. This took the form of speech acts, aggressive movements and gestures and/or physical disruptions that often led to feelings of anger, resentment and shame. These encounters potentially undermine any positive, ideological construction around the work, based for example on pride in a ‘job well done’. Therefore, ideological strategies to manage taint can be seen to be underpinned by material conditions and practices that can both support and undermine their effectiveness in creating moral worth.

\section{Conclusion}

This article has reviewed some of the key literatures around dirty work, an area that has arguably become increasingly relevant in the contemporary labour market with its proliferation of insecure work and 'bad' jobs (Atkinson et al, 2012; Bolton and Houlihan, 2007) and which has, in recent years, generated a growing level of academic interest. In so doing, we have sought to show a

tendency in the literature to place emphasis on the significance of task or role for identifying the forms that dirty work can take (i.e. based on physical, social and moral taint) as well as to highlight a dominant orientation towards a social constructionist interpretation. Influenced by 
anthropological accounts that see dirt as a social and cultural entity (e.g. Douglas, 1966) namely, as 'disorder' and 'matter out of place', we have seen how literature on dirty work has tended to place emphasis on the meanings attached to the work and on ideological strategies to help manage stigma and taint (e.g. through processes of reframing, refocusing, recalibrating) to the detriment of an appreciation of its more material, physical and embodied dimensions.

As we suggest, an 'embodied' understanding of dirty work is to appreciate the significance of the identity characteristics of workers (based on gender, class, race, nationality) as well as of the work's more material dimensions. In terms of the former, we have seen how some work may be devalued and seen as 'tainted' because of the identity characteristics of the worker. Thus, we have seen how the dirty work of care and of doing service are 'written onto' the bodies of women who are seen as 'naturally suited' for these roles. When men undertake service or caring roles their authoritative and untainted bodies are seen as 'matter out of place' so that the work is routinely revalued and, as Pullen and Simpson (2009) found, given higher meaning. A focus on task or role - as stable and largely disembodied categories - is to overlook the significance of 'embodied suitability' namely, how the value of the work (materialized in pay, conditions, prospects) depends in part on the social identity characteristics of the worker and how experiences of dirty work and perceptions of taint depend in part on these demographic and ‘bodily’ dimensions.

Further, we have argued for the importance of incorporating the material dimensions of dirt into an understanding of how dirty work is encountered and experienced - a materiality that is not 
fully integrated into socially constructionist conceptualizations of physical, social and moral taint. This can be seen in some of the complexities involved in the perception and management of physical staining, as visible and embodied manifestation of dirt, and how this is predicated upon a set of social relations based, for example, on gender, race or class. Finally, we have shown how the material can support ideological constructions around the work (e.g. where hard work and effort are a source of distinction and pride) while at the same time it can undermine positive reframing through the physical experience of monotony, strain and fatigue; through practices involving the handling (touch, smell) of disgusting matter that can adhere to clothing and the body; and/or through physical, face-to-face encounters with members of the public based on attitudes of disrespect. This suggests that more attention needs to be paid to how dirty work, as Hughes et al (2016) contend, is co-constituted by both the symbolic and the material and the ways in which they intertwine. In particular, an overemphasis on the discursive and the ideological in current accounts, based largely on the mobilization of meanings in affirmative terms, is to overlook how the material may impresses painfully on this group and how a reliance of the symbolic dimensions of the work may accordingly over-state positive attributions and constructions of work-based experiences. Taken together, 'embodying' dirty work is to produce a more comprehensive account that goes beyond a 'partial' view based on meanings attached to task or role. This has potential to enrich our understanding by including the constitutive roles of the identity categories of workers (e.g. based on gender, race, class) and of the material dimensions of the work in how it is encountered and experienced. 


\section{References}

Ashforth, B. and Kreiner, G. (1999) “How can you do it?” Dirty Work and the Challenge of Constructing a Positive Identity, Academy of Management Review, 24 (3): 413-434

Ashforth, B., Kreiner, G., Clark, M. and Fugate, M. (2007) Normalising dirty work: managerial tactics for countering occupational taint. Academy of Management Journal 50 (1): 149-174.

Ackroyd, S. and Crowdy, P. (1990) Can Culture be Managed? Working with Raw Material: The Case of the English Slaughterhouse Workers. Personnel Review, 19 (5): 3-14.

Anderson, B. (2000) Doing the Dirty Work: The Global Politics of Domestic Labour. London: Zed Books.

Ashforth, B. and Kreiner, G. (1999) “How can you do it?” Dirty Work and the Challenge of Constructing a Positive Identity. Academy of Management Review, 24 (3):413-434.

Ashforth, B. and Kreiner, G. (2014) Dirty Work and Dirtier Work: Differences in Countering Physical, Social and Moral Taint. Management and Organization Review, 10 (1): 81108.

Ashforth, B. and Kreiner, G. (2014) Contextualising Dirty Work: The Neglected Role of Cultural, Historical and Demographic Context, Journal of Management and Organization, 20 (4): 423-440 
Ashforth, B., Kreiner, G., Clark, M. and Fugate, M. (2007) Normalising dirty work: managerial tactics for countering occupational taint. Academy of Management Journal, 50 (1): 149_ 174.

Atkinson, W. Roberts, S. and Savage, M. (2012) Class Inequality in Austerity Britain: Power, Difference and Suffering. Basingstoke: Palgrave MacMillan

Bolton, S. and Houlihan, M. (2009) Work Matters: Critical Reflections on Contemporary Work. Basingstoke: Palgrave Macmillan.

Bolton, S. (2005) Women’s Work, Dirty Work: The Gynaecology Nurse as Other, Gender Work and Organization, 12 (2): 169-186

Britton, D. (1997) Gendered Organizational Logic: Policy and practice in men’s and women’s Prisons, Gender and Society, 11 (6): 796-818

Dant, T. and Bowles, D. (2003) Dealing with Dirt: Servicing and Repairing Cars, Sociological Review, www.socresonline.org.uk/8/2/dant.html

Dick, P. (2005) Dirty work designations: How police officers account for their use of coercive force. Human Relations, 58 (11): 1363-1390.

Douglas, M. (1966) Purity and Danger: An Analysis of Concepts of Pollution and Taboo. London: Routledge.

Duffy, M. (2007) Doing the Dirty Work: Gender, Race and Reproductive labour in Historical Perspective. Gender and Society, 21 (3): 313-336.

Goffman, E. (1963) Stigma, Harmondsworth: Penguin 
Grandy, G, and Mavin, S. (2012) Doing Gender in Dirty Work: Exotic Dancers' Construction of Self-enhancing Identities. In R. Simpson, N. Slutskaya, P. Lewis and H. Hopfl (Eds). Dirty Work: Concepts and Identities. Basingstoke: Palgrave, pp.91-112.

Hardy C and Thomas R (2015) Discourse in a material world. Journal of Management Studies 52(5): 680-96.

Hughes, E. (1962) Good People and Dirty Work. Social Problems, 10 (1): 3-11

Hughes, J., Simpson, R., Slutskaya, N., Simpson, A. and Hughes, K. (2016) 'Beyond the Symbolic: A Relational Approach to Dirty Work through a Study of Refuse Collectors and Street Cleaners, Work Employment and Society, 31 (1): 106-122

Jervis, L. (2001) The Pollution of Incontinence and the Dirty Work of Care Giving in a US Nursing Home. Medical Anthropology Quarterly, 15 (1): 84-99.

Lee-Treweek, G. (2012) Managing 'Dirty’ Migrant identities: Migrant labour and the neutralisation of Dirty Work through 'Moral’ Group Identity. In R. Simpson, N. Slutskaya, P. Lewis and H. Hopfl (Eds). Dirty Work: Concepts and Identities. Basingstoke: Palgrave, pp. 203-222.

McDowell, L. (2009) Working Bodies: Interactive Service Employment and Workplace Identities, Oxford: Blackwell

Newman, K. (1999) No Shame in my Game: The Working Poor in the Inner City. New York: Vintage.

Pullen, A. and Simpson, R. (2009) Managing Difference in Feminized Work: Men Otherness and Social Practice. Human Relations, 62(4 ): 561-587. 
Simpson, R., Slutskaya, N., Hughes, J. and Balta, M. (2014) Sacrifice and Distinction in Dirty Work: Men's Construction of Meanings in the Butcher Trade, Work Employment and Society, 28 (5): 754-770

Simpson, R., Slutskaya, N. and Hughes, J. (2012) Gendering and Embodying Dirty Work: Men Managing Taint in the Context of Nursing Care, in R. Simposn., N. Slutskaya, P. Lewis and H. Hopfl (Eds) Dirty Work: Concepts and Identities, Basingstoke: Palgrave MacMillan, 165-181

Simpson, R., Hughes, J. and Slutskaya, N. (2016) Gender, Class and Occupation: Working Class Men doing Dirty Work, Basingstoke: Palgrave MacMillan

Stacey, C. (2005) Finding Dignity in Dirty Work: the Constraints and Rewards of Low-wage Home Care Labour. Sociology of Health and Illness, 27 (6): 831-854

Stacey, C. (2011) The caring self: The work experiences of home care aides. Cornell University Press.

Toyoki, S. and Brown, A. (2014) Stigma, Identity and Power: Managing Stigmatised Identities through discourse. Human Relations, 67 (6): 715-737

Tracy, S. and Scott, C. (2006) Sexuality, Masculinity and Taint Management among Firefighters and Correctional Officers: Getting Down and Dirty with “America’s Heroes” and the “Scum of Law Enforcement.” Management Communication Quarterly, 20 (1): 6-38.

Tyler, M. (2011) Tainted Love: From Dirty work to Abject Labour in Soho’s sex shops. Human Relations, 64 (11): 1477-1500 
Vachhani, S. (2012) Stains, Staining and the Ethics of Dirty Work, in R. Simpson, N. Slutskaya, P. Lewis and H. Hopfl (Eds) Dirty Work: Concepts and Identities, Basingstoke: Palgrave McMillan, 33-48

Wolkowitz, C. (2006) Bodies at Work. London: Sage. 